\title{
Opportunities to maximize value with integrated palliative care
}

Jonathan Bergman ${ }^{1-3}$

Aaron A Laviana'

'Department of Urology, ${ }^{2}$ Department of Family Medicine, David Geffen School of Medicine at UCLA, ${ }^{3}$ Veterans Health Affairs-Greater Los Angeles, Los Angeles, CA, USA

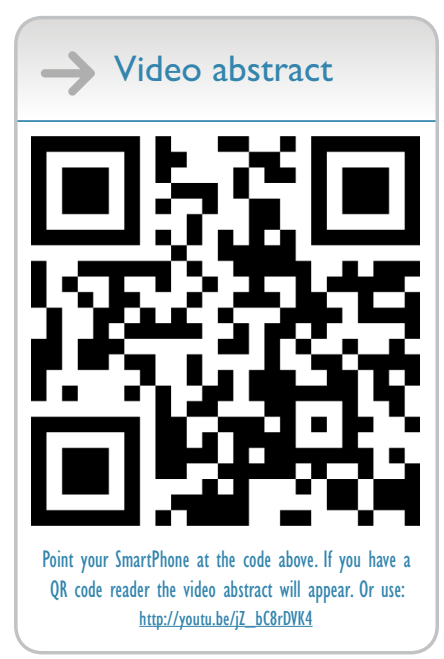

Correspondence: Jonathan Bergman Department of Urology, David Geffen School of Medicine at UCLA, 300 Stein Plaza, Third Floor, Los Angeles, CA 90095 , USA

Email jbergman@mednet.ucla.edu
This article was published in the following Dove Press journal:

Journal of Multidisciplinary Healthcare

5 May 2016

Number of times this article has been viewed

Abstract: Palliative care involves aggressively addressing and treating psychosocial, spiritual, religious, and family concerns, as well as considering the overall psychosocial structures supporting a patient. The concept of integrated palliative care removes the either/or decision a patient needs to make: they need not decide if they want either aggressive chemotherapy from their oncologist or symptom-guided palliative care but rather they can be comanaged by several clinicians, including a palliative care clinician, to maximize the benefit to them. One common misconception about palliative care, and supportive care in general, is that it amounts to "doing nothing" or "giving up" on aggressive treatments for patients. Rather, palliative care involves very aggressive care, targeted at patient symptoms, quality-of-life, psychosocial needs, family needs, and others. Integrating palliative care into the care plan for individuals with advanced diseases does not necessarily imply that a patient must forego other treatment options, including those aimed at a cure, prolonging of life, or palliation. Implementing interventions to understand patient preferences and to ensure those preferences are addressed, including preferences related to palliative and supportive care, is vital in improving the patient-centeredness and value of surgical care. Given our aging population and the disproportionate cost of end-of-life care, this holds great hope in bending the cost curve of health care spending, ensuring patientcenteredness, and improving quality and value of care. Level 1 evidence supports this model, and it has been achieved in several settings; the next necessary step is to disseminate such models more broadly.

Keywords: palliative care, end of life, integrated, urology

\section{Integrated palliative care}

Palliative care involves aggressively addressing and treating psychosocial, spiritual, religious, and family concerns and considering the overall psychosocial structures supporting a patient. Evidence has shown the significant benefit that palliative care provides to individuals with advanced disease. ${ }^{1,2}$ The concept of integrated palliative care removes the either/or decision a patient needs to make: she need not decide if she wants either aggressive chemotherapy from her oncologist or symptom-guided palliative care but rather can be comanaged by several clinicians, including a palliative care clinician, to maximize the benefit to her. In this multidisciplinary model, palliative care clinicians, oncologists, primary care clinicians, and others work in concert to care for patients with advanced diseases. ${ }^{3,4}$

Traditionally, surgeons were not involved in integrated palliative care paradigms. However, recent efforts have worked toward including surgeons in the multidisciplinary team approach, when appropriate. ${ }^{5}$ Surgeons spend many resources on individuals 
at the end of life, but we do not effectively incorporate the patient in considering what would benefit the patient most. If, as a society, we are willing to invest $>\$ 90,000$ in a man dying of prostate cancer (the cost of sipuleucel-T, one of many expensive new therapies), would that man prefer we spend those resources extending his life by 4 months with no improvement in quality of life or that we invest some proportion of those resources in home support and symptom relief? ${ }^{6}$ Or, are there other ways that could improve patientcenteredness by ensuring that we understand the individual needs of each patient and respond to those needs? Where does palliative care fit? How can we ensure that our efforts are multidisciplinary and patient-centered? Integrated palliative care is a novel model that may address many of these shortcomings.

The health-related quality-of-life burdens related to surgical care are unique and may impose particular harms, yet surgeons have lagged in efforts to foster better supportive and palliative care management. A critical mass of research has isolated two variables that decrease cost and improve quality at the end of life: 1) addressing patient goals and 2) integrating palliative care early into the management of patients with cancer. $^{7-12}$ When patient goals are addressed, cost of care is reduced by one-third, with improved quality of life and quality of death. Randomized trials have demonstrated the benefits of early palliative care for patients with cancer, including lower rates of emergency department visits, fewer hospital admissions and intensive care unit (ICU) stays on admission, lower cost, fewer in-hospital deaths, improved satisfaction with care, better quality of life, less severe symptoms, improved mood, less aggressive end-of-life care, and longer median survival. ${ }^{13}$

\section{Recommendations from the Institute of Medicine and legislative efforts}

The Institute of Medicine (IOM) recently published a report on Dying in America. The IOM declaimed, "Improved care for people near the end of life is a goal within the nation's reach." ${ }^{14}$ To improve quality and honor individual preferences near the end of life, the IOM recommended strategies to improve five vital components of care: 1) the delivery of person-centered, family-oriented end-of-life care; 2) clinician-patient communication and advance care planning; 3) professional education and development; 4) policies and payment systems to support high-quality endof-life care; and 5) public education and engagement. Palliative care in surgical populations holds immense potential to improve patient-centeredness, quality of care, and value of care.

Current bipartisan federal legislative proposals, including the Palliative Care and Hospice Education and Training Act and the Patient Centered Quality Care for Life Act, aim to buttress palliative services for individuals with advanced disease. The relationship between a patient and his urologist is often deeper and more intricately woven than with any other practitioner. A man dying of prostate cancer, for instance, has known his urologist for an average of 13 years. ${ }^{15}$ Not all surgeons have relationships that are as long as those that urologists may enjoy with their patients dying of prostate cancer, but all surgeons are intimately involved with their patients and should be incorporated into the team addressing patient needs at the end of life. Several models in surgical subspecialties have utilized integrated palliative care, with great success; the intimate and meaningful relationship between the surgeon and patient is not limited to urology. ${ }^{16,17}$ Where these models have been employed, surgeons have expressed satisfaction with the care received and the model used to achieve that care. Additionally, integrated palliative care has been used to formalize advance care planning for appropriate patients. ${ }^{18}$ This is especially important so that patient goals of care are clarified, and patients are not subsequently provided with care (such as intubation, ICU stay, etc) that they may not want. Therefore, surgical clinics, may serve as ideal targets to introduce palliative care, improving quality, and reducing cost as death approaches.

\section{Cost and value - opportunities for integrated palliative care}

The primary purpose of integrated palliative care is not cost. Palliative care focuses on quality of life, symptom management, and psychosocial support, a patient-centered approach through which reduced cost or improved value is a secondary byproduct, not a primary concern. Interventions both in the United States and internationally have been successful in utilizing patient care to improve outcomes for patients. These outcomes include quality of life, pain management, psychosocial health, family assessment of care and bereavement, and even survival. ${ }^{19,20}$

Additionally, as a secondary byproduct of integrated palliative care, gains in value may be seen. Value refers to quality divided by cost, and maximizing value includes delivering high-quality care while limiting cost if that cost does not add benefit to a patient. ${ }^{21-23}$ The importance of improving quality and reducing cost at the end of life is underscored by the current value of end-of-life care, which leaves significant 
avenues for improvement. ${ }^{24}$ In the United States, failure to comprehensively address end-of-life issues leads to highcost, mediocre-quality care. ${ }^{25}$ One quarter of our health care resources in the United States are expended in the last year of life, yet quality of end-of-life care warrants reform. ${ }^{26,27}$ Patient goals are addressed shoddily, and when value-congruent care is subsequently not delivered, cost increases (with significant regional variation) while quality suffers. ${ }^{28,29}$ Broadening discussions about end-of-life care, enhancing integration, and improving patient-centeredness during the final chapter of life are central goals defined by many of the agencies charged with improving national health. ${ }^{30}$ The Agency for Healthcare Research and Quality, as well as the National Cancer Institute, has prioritized initiating national symposia to discuss key issues in improving end-of-life care. The National Committee for Quality Assurance identified integration of end-of-life care as a key component in creating a patient-centered medical home. The mission statement of the Patient-Centered Outcomes Research Institute created under the Patient Protection and Affordable Care Act opens with the need to "help people make informed healthcare decisions, and improve healthcare delivery and outcomes." ${ }^{31-33}$

The unsustainable cost of health care, especially endof-life care, is well documented. Health care expenditures currently exceed $\$ 2.2$ trillion, accounting for $\sim 18 \%$ of the gross domestic product. ${ }^{34-37}$ The proportion of the gross domestic product spent on health care is rising at an alarming rate. Overall, Medicare spending is rising by almost $4 \%$ annually, with significant demographic variation. The slice of the health care pie that drives cost most precipitously is endof-life care. Approximately one-quarter of Medicare expenditures are attributable to the $5 \%$ of beneficiaries who die each year, and acute care in the last 30 days of life accounts for almost $80 \%$ of costs incurred in the final year of life. ${ }^{38}$ Most of these costs are spent administering life-sustaining care, which often is not value congruent. Decreasing aggressive care at the end of life, by reducing frequent hospital and ICU admissions, can lead to decreased use of cardiac catheterization, dialysis, ventilators, and pulmonary artery monitors, significantly reducing end-of-life cost.

Delivering high-quality, integrated care at the end of life is likely to reduce health care spending as death approaches. ${ }^{27}$ Level 1 evidence suggests that compared with patients who receive regular care, those who receive early palliative care have higher quality of life, lower depression, less aggressive end-of-life care, and longer survival. Poor-quality care occurs when "practices of known effectiveness are being underutilized, practices of known ineffectiveness are being overutilized, and when services of equivocal effectiveness are being utilized in accordance with provider rather than patient preferences." Quality of end-of-life care indicators endorse referring individuals to hospice in a timely fashion, avoiding unnecessary emergency room visits, intensive care stays, and inpatient admissions, and discontinuing chemotherapy when death is imminent. Use of chemotherapy at the very end of life increases cost but does not improve survival. ${ }^{39}$ The reasons individuals choose aggressive care at the end of life have yet to be clearly elucidated, but significant variation exists in the intensity of end-of-life care, and this variation is often a result of physician practices, not patient preferences. Significant variation exists in aggressive chemotherapy use at the end of life and in hospice admissions at the end of life. Appropriate, high-quality end-of-life care occurs when end-of-life goals are addressed and typically leads to reduced cost and improved quality of life and quality of death. Highcost, life-sustaining care at the end of life, on the other hand, is associated with decreased quality of death. Patients who do receive aggressive treatment at the end of life often have unrealistic expectations regarding the benefits of aggressive treatments, suggesting that an avenue for improvement exists in physician-patient communication. Timely use of hospice and palliative care significantly reduces hospital costs for individuals who do and do not die in the hospital. Thus, assessing patient goals is central to delivering valuecongruent care..$^{40,41}$

Interventions aimed at improving the quality and lowering the cost of end-of-life care should focus on improving communication between providers and patients and on ensuring that each individual's end-of-life goals are elucidated; integrated palliative care can help achieve these goals. ${ }^{42}$ Numerous studies have shown that addressing end-of-life goals with patients can rationalize and contain costs, by reducing undesired, aggressive care without rationing or denying individuals aggressive care they may want. Patient-reported outcomes have shown that if a discussion about end-of-life goals is had at baseline, the cost of care in the last week of life care is reduced by $36 \%$ (from $\$ 2,917$ to $\$ 1,876$ ). ${ }^{29}$ Higher costs are associated with more physical distress and worse quality of death in the final week. Those who reported end-of-life discussions had less physical distress in the last week of life. They were also less likely to undergo mechanical ventilator use and more likely to be referred to hospice earlier. They were less likely to be admitted to or die in an ICU. No differences in survival were seen. Data from a longitudinal, multi-institutional cohort study likewise showed that end-of-life conversations between patients and physicians 
are associated with fewer life-sustaining procedures and lower rates of ICU admission. Integration of palliative care leads to lower inpatient cost, and inpatient collaboration with palliative care teams results in lower pharmacy and laboratory expenses, decreased lengths of stay, and fewer admissions to the ICU. The cost savings are substantial. Outpatient palliative care can decrease cost by up to $33 \%$ in some patients, by decreasing acute care services, minimizing hospitalizations, and decreasing emergency room visits. ${ }^{43-45}$ Thus, delivering value-congruent care at the end of life by addressing goals with all patients (but denying care to none) decreases the cost of care and improves quality of life without reducing its quantity. Implementing interventions to achieve these goals is vital to improving the value of the health care we deliver, and achieving success in a surgical clinic can uniquely inform future interventions to be pursued for broad implementation.

The framework for how palliative care visits can be structured in this setting was laid out in the National Consensus Project for Quality Palliative Care. Palliative care clinicians can use a template from the electronic health record to document care provided, including assessment of physical and psychosocial symptoms, establishment of goals of care, assistance with decision making regarding treatment, and coordination of care based on patient needs.

\section{Case example of the potential impact of integrated palliative care}

One example of the impact that integrated palliative care can have can be drawn from men with prostate cancer. The importance of developing a more patient- and family-centered decision-making approach for men with prostate cancer and including supportive, palliative, and end-of-life considerations is underscored by the prevalence of the disease and the significant variability in the effectiveness and costs of treatment options. General treatment options, such as desire for mechanical ventilation, resuscitation status, desire to pursue hospice care when appropriate, and desire for aggressive but not curative treatments, as well as several specific treatment choices, need to be made thoughtfully and on an individualized basis. New costly therapies have added to the complexity of decisions patients, families, and providers must navigate; the example of painful bone metastasis is highlighted for illustration.

Individuals with bone metastases can choose among no treatment, pain-directed treatment with single-dose fractionated radiotherapy, pain-directed treatment with a full dose of radiotherapy, and therapies to reduce the risk of skeletal-related events. These events can be reduced with denosumab, which is injected subcutaneously but carries a $2 \%$ risk of osteonecrosis of the jaw, or with zoledronic acid, which involves monthly drip infusions at an infusion center, or with oral bisphosphonates, which are less potent in lowering the risk of skeletal-related events but less cumbersome to administer. Cost varies significantly among the options. Similar complex trade-offs need to be made regarding other treatment choices, discussed in the Implementation science section. ${ }^{46,47}$

Table 1 displays some of the treatment options available for men with castrate-resistant prostate cancer, side effects,

Table I Treatment options to be considered by men with castrate-resistant prostate cancer

\begin{tabular}{|c|c|c|c|c|c|}
\hline Treatment & Side effects & Quality of life benefit & $\begin{array}{l}\text { Average survival } \\
\text { benefit }\end{array}$ & $\begin{array}{l}\text { Yearly cost } \\
\text { (USD) }\end{array}$ & $\begin{array}{l}\text { Logistic } \\
\text { burden }\end{array}$ \\
\hline Abiraterone & $\begin{array}{l}\text { Fluid retention, hypertension, } \\
\text { hypokalemia }\end{array}$ & $\begin{array}{l}\text { Delays progression of pain } \\
\text { and } \mathrm{QOL} \text { deterioration if } \\
\text { taken with prednisone }\end{array}$ & 4 months & $\$ 60,000$ & Daily oral \\
\hline Sipuleucel-T & Dizziness, arthralgia & None & 4 months & $\$ 93,000$ & $\begin{array}{l}\text { Biweekly infusion } \\
\text { after leukopheresis }\end{array}$ \\
\hline Enzalutamide & Seizures, hallucinations & $\begin{array}{l}\text { Improved QOL when } \\
\text { administered after docetaxel }\end{array}$ & $2-5$ months & $\$ 90,000$ & Daily oral \\
\hline Radium 223 & Myelosuppression, diarrhea & None & $3-4$ months & $\$ 70,000$ & Monthly infusion \\
\hline $\begin{array}{l}\text { Docetaxel } \\
\text { (first-line chemo) }\end{array}$ & Hair loss, neuropathy & $\begin{array}{l}\text { Improved QOL, reduced } \\
\text { pain }\end{array}$ & $3-4$ months & $\$ 15,000$ & $\begin{array}{l}\text { Every 3-week } \\
\text { hourly infusion }\end{array}$ \\
\hline $\begin{array}{l}\text { Cabazitaxel } \\
\text { (second-line chemo) }\end{array}$ & Neutropenia, hypersensitivity & Unknown & 3 months & $\$ 45,000$ & $\begin{array}{l}\text { Every 3-week } \\
\text { hourly infusion }\end{array}$ \\
\hline Cabozantinib & $\begin{array}{l}\text { Fatigue, hypertension, } \\
\text { hand-foot-mouth disease }\end{array}$ & Decreased bone pain & Unknown & $\$ 120,000$ & Daily oral \\
\hline Palliative care & None & Unstudied in this population & $\begin{array}{l}\text { Unstudied in this population; } \\
3 \text { months in individuals with } \\
\text { metastatic lung cancer }\end{array}$ & Variable & Variable \\
\hline
\end{tabular}

Abbreviation: QOL, quality of life. 
Table 2 Androgen deprivation options for men with castrate-resistant prostate cancer

\begin{tabular}{|c|c|c|c|c|}
\hline $\begin{array}{l}\text { Method of androgen } \\
\text { deprivation }\end{array}$ & Unique benefits & Unique side effects & Yearly cost & Logistic burden \\
\hline Surgical castration & $\begin{array}{l}\text { Avoidance of ongoing } \\
\text { interventions }\end{array}$ & Surgical morbidity & $\$ 4,000$ (once) & $\begin{array}{l}\text { One-time surgical } \\
\text { procedure }\end{array}$ \\
\hline Leuprolide & Lowest cost of injectables & Injection site pain & $\$ 2,400$ & $\begin{array}{l}\text { Every } 3 \text { months } \\
\text { subcutaneous }\end{array}$ \\
\hline Leuprolide long acting & Least frequent dosing & $\begin{array}{l}\text { Injection site pain, irreversible } \\
\text { for } 6 \text { months }\end{array}$ & $\$ 6,000$ & $\begin{array}{l}\text { Every } 6 \text { months } \\
\text { subcutaneous }\end{array}$ \\
\hline Bicalutamide & $\begin{array}{l}\text { Reversible if side effects not } \\
\text { tolerated }\end{array}$ & $\begin{array}{l}\text { Less effective as monotherapy } \\
\text { than other castration options }\end{array}$ & $\$ 365$ & Daily oral \\
\hline Degarelix & $\begin{array}{l}\text { Castration achieved by day } 3 \\
\text { (7-14 days with leuprolide) }\end{array}$ & Cardiac arrhythmias & $\$ 6,000$ & $\begin{array}{l}\text { Monthly } \\
\text { subcutaneous }\end{array}$ \\
\hline
\end{tabular}

quality-of-life impacts, average survival benefit, cost, and logistic burden. This is one example of the complex decision making that a patient must navigate when facing advanced disease. Understanding each of the dimensions of those decisions, including their impact on survival, quality of life, and logistic burden, is important to help each patient make the decision that is best for him.

\section{Implementation science - achieving integrated palliative care}

Implementing interventions to understand patient preferences and to ensure those preferences are addressed, including preferences related to palliative and supportive care, is vital to improving the patient-centeredness and value of surgical care. Given our aging population and the disproportionate cost of end-of-life care, this holds great hope in bending the cost curve of health care spending, ensuring patient-centeredness, and improving quality and value of care. Level 1 evidence supports this model, and it has been achieved in several settings; the next necessary step is to disseminate such models more broadly. ${ }^{10,12,48,49}$

Palliative care in geriatric surgical populations holds immense potential to improve patient-centeredness, quality of care, and value of care. For many patients, especially in older populations with multiple comorbidities - individuals who are being managed by a surgeon but have many competing ailments and priorities - surgeons should be part of the multidisciplinary teams that integrate palliative care into the comprehensive management of patients. This holds promise in preserving quality of life in patients with chronic diseases, improving interdisciplinary care and patientcenteredness, and maximizing quality of life for patients and families. Current paradigms in palliative care have been accepted based on level 1 evidence, but the current paradigm can be expanded and shifted to surgical populations, where opportunities for improvement abound. This has been achieved in some settings but is not the standard of care in the United States for all patients with advanced diseases. Ideally, consideration of integration of palliative care into the management of geriatric patients with surgical problems would occur early in the trajectory of the disease, likely in an ambulatory setting.

One pilot feasibility study has shown the potential of integrating palliative care in a surgical oncology setting. In that study, surgeons partnered with patients, families, and palliative care clinicians to establish an integrated clinic at our institution, in which palliative care clinicians attended to urologic patients with metastatic disease in the urology clinic. ${ }^{50}$ Urology providers completed an educational module and were prompted by point-of-care reminders to address goals of care with all patients, assess pain and depression, and consider a palliative care consultation. The palliative care clinicians then treated patients at the point of care, in the urology clinic. The intervention was enthusiastically endorsed by patients and clinicians, the plan proved feasible, and patient and family satisfaction has been high. Conducting the palliative care consultation at the point of care, in our urology clinic, has been enthusiastically adopted by our palliative care clinicians, urology providers, and patients. Clinicians found that referring a patient to palliative care in the urology clinic was feasible and appropriate. Patients were receptive to supportive care, and clinicians perceived that quality of care improved following the intervention. However, further tools to improve decision making and focus on clinical discussions are needed to achieve optimal patient-centered outcomes.

\section{Culture and palliative care}

One common misconception about palliative care, and supportive care in general, is that it amounts to "doing nothing" 
or "giving up" on aggressive treatments for patients. Rather, palliative care involves very aggressive care, targeted at patient symptoms, quality of life, psychosocial needs, family needs, and others. ${ }^{51}$ Integrating palliative care into the care plan for individuals with advanced diseases does not imply that patients must forego any treatment option, including those aimed at cure, prolonging of life, or palliation. Indeed, patients who are treated by palliative care clinicians often undergo treatments and hospitalizations, if their individual goals of care support such steps, and do not need to choose between aggressive care and palliative care. ${ }^{52}$

Achieving a cultural understanding of this comanagement model is vital to successfully integrating palliative care within any institution. If oncologists, surgeons, or others believe that patient options will be limited because of the involvement of the palliative care team, they are less likely to embrace supportive care needs. However, multiple models have shown the benefits of continued comanagement (when appropriate) by oncologists, primary care physicians, palliative care clinicians, and even surgeons. The visibility of palliative care and the benefits it affords have increased in the past decades, improving our ability to work toward expanding the role of palliative care for appropriate patients. One current limitation includes workforce shortages, which need to be aggressively addressed in the near future.

\section{Education about integrated palliative care}

Integrated palliative care is neither a novel concept nor fully familiar to all clinicians providing care to individuals with advanced diseases. To that end, educating clinicians about integrated palliative care is vital to achieving broad implementation and utilization when appropriate. The need to address patient-centered needs and focus on patient goals and symptoms (rather than solely on life-prolonging treatments) are vital paradigms that need to be taught not only in a medical setting but also in undergraduate and graduate training. This helps lay the foundation for subsequent appropriate care delivery models. In Australia, palliative care content has been introduced into undergraduate curricula for nursing, with great success. ${ }^{53}$ It has also been introduced in other settings, improving broad understanding of the goals of palliative care. ${ }^{54}$

Numerous initiatives have aimed at improving end-of-life education, including curricula using web-based modules. ${ }^{55,56}$ Problem-based modules are particularly adept at teaching the concept of integrated palliative care as they take a clinician through a sample patient she may see in her clinic. The
National Cancer Institute has identified the importance of educating clinicians about end-of-life care. Prior interventions have shown that an intensive communication skills retreat can lead to changes in communication behaviors and changes in the perceived relationship between practitioner and patient. A formalized curriculum to educate clinicians about end-of-life care has been created by the American Medical Association Institute for Ethics' Education for Physicians on End-of-Life Care (EPEC ${ }^{\mathrm{TM}}$ ) Project. The project aimed to reach $>120,000$ clinicians and was shown to be usable, respected, and high in quality. ${ }^{57} \mathrm{~A}$ curriculum specific for surgeons has been developed in a separate setting and has proved useful in affecting physician knowledge and attitudes about palliative and end-of-life care.

Web-based education is a natural extension of inquirybased pedagogy and can be adapted to different audiences and changing standards over time; it has been shown to be more effective than "banking" educational frameworks, in which students are mere receptacles to be filled with information. As the influential Brazilian philosopher and educator, Paulo Freire, explained in Pedagogy of the Oppressed, the goal of education should be inquiry based rather than banking the "action and reflection of men and women upon their world in order to transform it." Educating physicians in this manner, by engaging them in real-world situations and applying possible interventions (commonly referred to as "education by praxis"), holds promise in transforming students into vessels of change. In medical education, data specifically studying the efficacy of web-based educational modules have yet to be reported. A web-based model builds on previous educational approaches that have used self-study modules to improve clinical care and provider knowledge. The approach utilizes a problem-based learning module that simulates clinical interactions, building on the concepts advanced by Freire, John Dewey, and other progressive educational theorists. Problem-based pedagogy, such as the module developed for end-of-life care, has been shown to be effective at teaching core competencies, specific content, and constructive teamwork. Applying problem-based learning to end-of-life care could prove useful in improving clinician knowledge and attitudes toward end-of-life care and in transforming students into vessels for improving health care.

\section{Role of the integrated health care team}

Part of the goal of palliative care is to achieve patient-centered care, including symptoms control, psychosocial health, spiritual care, and family support. This is best achieved in a 
multidisciplinary manner, which requires an integrated health care team. Nurses, chaplains, and social workers are vital parts of this team, and integration of multidisciplinary care givers has been shown to maximize the physical and mental health benefits of integrated palliative care.

\section{Conclusion}

Improving integration of palliative care into the management of individuals with advanced diseases holds promise in improving patients' quality of life, pain, depression, psychosocial health, and the health of the family. The mounting evidence about the broad-reaching benefit of palliative care has led to meaningful discussions about how to appropriately achieve integrated palliative care as broadly as possible where appropriate. Disseminating interventions to broaden discussions about end-of-life care and improving integration and patient-centeredness during the final chapter of life are central goals defined by many of the agencies charged with improving national health. The IOM and the National Committee for Quality Assurance identified integration of end-of-life care as a key component in improving care and creating a patient-centered medical home. The Agency for Healthcare Research and Quality and the National Cancer Institute have prioritized initiating national symposia to discuss key issues in improving end-of-life care. The mission statement of the Patient-Centered Outcomes Research Institute created under the Patient Protection and Affordable Care Act opens with the need to "help people make informed healthcare decisions, and improve healthcare delivery and outcomes."

Integrated palliative care is one way in which patientcenteredness at the end of life can be improved. The benefits of palliative care have now been demonstrated in multiple models, and the next step in maximizing the benefit of palliative care will be to develop methods to achieve cultural changes in health care settings and to broadly systematize methods of integrating palliative care for individuals with advanced diseases.

\section{Disclosure}

The authors report no conflicts of interest in this work.

\section{References}

1. Lamas DJ, Owens RL, Bernacki RE, Block SD. Palliative care: a core competency for intensive care unit doctors. Am J Respir Crit Care Med. 2014;189:1569.

2. Bernacki RE, Ko DN, Higgins P, et al. Improving access to palliative care through an innovative quality improvement initiative: an opportunity for pay-for-performance. J Palliat Med. 2012;15:192-199.
3. Dy SM, Walling AM, Mack JW, et al. Evaluating the quality of supportive oncology using patient-reported data. J Oncol Pract. 2014;10:e223-e230.

4. Smith TJ, Temin S, Alesi ER, et al. American Society of Clinical Oncology provisional clinical opinion: the integration of palliative care into standard oncology care. J Clin Oncol. 2012;30:880-887.

5. Cooper Z, Corso K, Bernacki R, Bader A, Gawande A, Block S. Conversations about treatment preferences before high-risk surgery: a pilot study in the preoperative testing center. J Palliat Med. 2014;17:701-707.

6. Chambers JD, Neumann PJ. Listening to Provenge - what a costly cancer treatment says about future Medicare policy. $N$ Engl J Med. 2011;364:1687-1689.

7. Mack JW, Cronin A, Taback N, et al. End-of-life care discussions among patients with advanced cancer: a cohort study. Ann Intern Med. 2012;156:204-210.

8. Mack JW, Cronin A, Keating NL, et al. Associations between end-of-life discussion characteristics and care received near death: a prospective cohort study. J Clin Oncol. 2012;30:4387-4395.

9. Bauman JR, Temel JS. The integration of early palliative care with oncology care: the time has come for a new tradition. J Natl Compr Canc Netw. 2014;12:1763-1771; quiz 1771.

10. Parikh RB, Temel JS. Early specialty palliative care. $N$ Engl J Med. 2014;370:1075-1076.

11. Yoong J, Park ER, Greer JA, et al. Early palliative care in advanced lung cancer: a qualitative study. JAMA Intern Med. 2013;173: 283-290.

12. Temel JS, Greer JA, Muzikansky A, et al. Early palliative care for patients with metastatic non-small-cell lung cancer. $N$ Engl J Med. 2010;363:733-742.

13. Bernacki R, Hutchings M, Vick J, et al. Development of the Serious Illness Care Program: a randomised controlled trial of a palliative care communication intervention. BMJ Open. 2015;5:e009032.

14. Tulsky JA. Improving quality of care for serious illness: findings and recommendations of the institute of medicine report on dying in America. JAMA Intern Med. 2015;175:840-841.

15. Pound CR, Partin AW, Eisenberger MA, Chan DW, Pearson JD, Walsh PC. Natural history of progression after PSA elevation following radical prostatectomy. JAMA. 1999;281:1591-1597.

16. Mosenthal AC, Weissman DE, Curtis JR, et al. Integrating palliative care in the surgical and trauma intensive care unit: a report from the improving palliative care in the intensive care unit (IPAL-ICU) project advisory board and the center to advance palliative care. Crit Care Med. 2012;40:1199-1206.

17. Larson AM, Curtis JR. Integrating palliative care for liver transplant candidates: "too well for transplant, too sick for life". JAMA. 2006;295:2168-2176.

18. Ahluwalia SC, Tisnado DM, Walling AM, et al. Association of early patient-physician care planning discussions and end-of-life care intensity in advanced cancer. J Palliat Med. 2015;18(10):834-841.

19. Lynch T, Connor S, Clark D. Mapping levels of palliative care development: a global update. J Pain Symptom Manage. 2013;45:1094-1106.

20. Callaway M, Foley KM, De Lima L, et al. Funding for palliative care programs in developing countries. J Pain Symptom Manage. 2007;33:509-513.

21. Cheung MC, Earle CC, Rangrej J, et al. Impact of aggressive management and palliative care on cancer costs in the final month of life. Cancer. 2015;121:3307-3315.

22. Malin JL, O'Neill SM, Asch SM, et al. Quality of supportive care for patients with advanced cancer in a VA medical center. J Palliat Med. 2011;14:573-577.

23. Gomes B, McCrone P, Hall S, Koffman J, Higginson IJ. Variations in the quality and costs of end-of-life care, preferences and palliative outcomes for cancer patients by place of death: the QUALYCARE study. BMC Cancer. 2010;10:400.

24. Lorenz KA, Dy SM, Naeim A, et al. Quality measures for supportive cancer care: the Cancer Quality-ASSIST Project. J Pain Symptom Manage. 2009;37:943-964. 
25. Walling AM, Tisnado D, Asch SM, et al. The quality of supportive cancer care in the veterans affairs health system and targets for improvement. JAMA Intern Med. 2013;173:2071-2079.

26. Garrido MM, Balboni TA, Maciejewski PK, Bao Y, Prigerson HG. Quality of life and cost of care at the end of life: the role of advance directives. J Pain Symptom Manage. 2015;49:828-835.

27. Teno JM, Gozalo PL, Bynum JP, et al. Change in end-of-life care for Medicare beneficiaries: site of death, place of care, and health care transitions in 2000, 2005, and 2009. JAMA. 2013;309:470-477.

28. Kaldjian LC, Curtis AE, Shinkunas LA, Cannon KT. Goals of care toward the end of life: a structured literature review. Am J Hosp Palliat Care. 2008;25:501-511.

29. Zhang B, Wright AA, Huskamp HA, et al. Health care costs in the last week of life: associations with end-of-life conversations. Arch Intern Med. 2009;169:480-488.

30. Peppercorn JM, Smith TJ, Helft PR, et al; American Society of Clinical Oncology. American society of clinical oncology statement: toward individualized care for patients with advanced cancer. J Clin Oncol. 2011;29:755-760.

31. Shaw FE, Asomugha CN, Conway PH, Rein AS. The Patient Protection and Affordable Care Act: opportunities for prevention and public health. Lancet. 2014;384:75-82.

32. Ryan AM, Mushlin AI. The Affordable Care Act's payment reforms and the future of hospitals. Ann Intern Med. 2014;160:729-730.

33. Jaffe HW, Frieden TR. Improving health in the U S A: progress and challenges. Lancet. 2014;384:3-5.

34. Yabroff KR, Francisci S, Mariotto A, Mezzetti M, Gigli A, Lipscomb J. Advancing comparative studies of patterns of care and economic outcomes in cancer: challenges and opportunities. J Natl Cancer Inst Monogr. 2013;2013:1-6.

35. Yabroff KR, Lund J, Kepka D, Mariotto A. Economic burden of cancer in the United States: estimates, projections, and future research. Cancer Epidemiol Biomarkers Prev. 2011;20:2006-2014.

36. Yabroff KR, Warren JL, Schrag D, et al. Comparison of approaches for estimating incidence costs of care for colorectal cancer patients. Med Care. 2009;47:S56-S63.

37. Yabroff KR, Lamont EB, Mariotto A, et al. Cost of care for elderly cancer patients in the United States. J Natl Cancer Inst. 2008;100:630-641.

38. Riley GF, Lubitz JD. Long-term trends in Medicare payments in the last year of life. Health Serv Res. 2010;45:565-576.

39. Walling AM, Asch SM, Lorenz KA, et al. The quality of care provided to hospitalized patients at the end of life. Arch Intern Med. 2010;170: $1057-1063$

40. Lendon JP, Ahluwalia SC, Walling AM, et al. Measuring experience with end-of-life care: a systematic literature review. J Pain Symptom Manage. 2015;49(5):904-915. e1-e3.

41. Morden NE, Chang CH, Jacobson JO, et al. End-of-life care for Medicare beneficiaries with cancer is highly intensive overall and varies widely. Health Aff (Millwood). 2012;31:786-796.

42. Sprung CL, Truog RD, Curtis JR, et al. Seeking worldwide professional consensus on the principles of end-of-life care for the critically ill. The consensus for worldwide end-of-life practice for patients in intensive care units (WELPICUS) study. Am J Respir Crit Care Med. 2014;190:855-866.
43. Morrison RS, Penrod JD, Cassel JB, et al; Palliative Care Leadership Centers' Outcomes Group. Cost savings associated with US hospital palliative care consultation programs. Arch Intern Med. 2008;168: 1783-1790.

44. Penrod J, Morrison RS, Meier DE. Studying the effectiveness of palliative care. JAMA. 2008;300:1022-1023. ; author reply 1023-1024.

45. Penrod JD, Deb P, Luhrs C, et al. Cost and utilization outcomes of patients receiving hospital-based palliative care consultation. $J$ Palliat Med. 2006;9:855-860.

46. Smith MR, Saad F, Coleman R, et al. Denosumab and bone-metastasisfree survival in men with castration-resistant prostate cancer: results of a phase 3, randomised, placebo-controlled trial. Lancet. 2012;379: $39-46$.

47. Smith MR, Egerdie B, Hernandez Toriz N, et al; Denosumab HALT Prostate Cancer Study Group. Denosumab in men receiving androgen-deprivation therapy for prostate cancer. $N$ Engl $J$ Med. 2009;361:745-755.

48. Levy M, Smith T, Alvarez-Perez A, et al. Palliative care version 1.2016. J Natl Compr Canc Netw. 2016;14:82-113.

49. Parikh RB, Kirch RA, Smith TJ, Temel JS. Early specialty palliative care - translating data in oncology into practice. $N$ Engl J Med. 2013;369:2347-2351.

50. Bergman J, Ballon-Landa E, Lorenz KA, et al. Community-partnered collaboration to build an integrated palliative care clinic: the view from urology. Am J Hosp Palliat Care. Epub 2014 Oct 16.

51. Callahan D. End-of-life care: a philosophical or management problem? J Law Med Ethics. 2011;39:114-120.

52. Dow LA, Matsuyama RK, Ramakrishnan V, et al. Paradoxes in advance care planning: the complex relationship of oncology patients, their physicians, and advance medical directives. $J$ Clin Oncol. 2010;28:299-304.

53. Ramjan JM, Costa CM, Hickman LD, Kearns M, Phillips JL. Integrating palliative care content into a new undergraduate nursing curriculum: the University of Notre Dame, Australia - Sydney experience. Collegian. 2010;17:85-91.

54. Chiarelli PE, Johnston C, Osmotherly PG. Introducing palliative care into entry-level physical therapy education. $J$ Palliat Med. 2014;17:152-158.

55. Bergman J, Lorenz KA, Ballon-Landa E, et al. A scalable web-based module for improving surgical and medical practitioner knowledge and attitudes about palliative and end-of-life care. $J$ Palliat Med. 2015; 18:415-420.

56. Bergman J, Ballon-Landa E, Lerman SE, Kwan L, Bennett CJ, Litwin MS. Engaging physician learners through a web-based platform: individualized end-of-life education. Am J Hosp Palliat Care. Epub 2015 Aug 9.

57. Grant M, Elk R, Ferrell B, von Gunten CF. Current status of palliative care - clinical implementation, education, and research. CA Cancer J Clin. 2009;59:327-335.
Journal of Multidisciplinary Healthcare

\section{Publish your work in this journal}

The Journal of Multidisciplinary Healthcare is an international, peerreviewed open-access journal that aims to represent and publish research in healthcare areas delivered by practitioners of different disciplines. This includes studies and reviews conducted by multidisciplinary teams as well as research which evaluates the results or conduct of such teams or
Dovepress

healthcare processes in general. The journal covers a wide range of areas and welcomes submissions from practitioners at all levels, from all over the world. The manuscript management system is completely online and includes a very quick and fair peer-review system. Visit http://www.dovepress.com/testimonials.php to read real quotes from published authors. 